OPEN ACCESS

Edited by: Philip J. Seddon,

University of Otago, New Zealand

Reviewed by:

Guangshun Jiang, Northeast Forestry University, China

Nicholas W. Pilfold,

San Diego Zoo Institute for Conservation Research, United States

*Correspondence: Julie K. Young julie.young@usu.edu

Specialty section: This article was submitted to Animal Conservation,

a section of the journal

Frontiers in Conservation Science

Received: 15 September 2021

Accepted: 28 January 2022

Published: 07 March 2022

Citation:

Doden E, Budy P, Avgar T and Young JK (2022) Movement Patterns of Resident and Translocated Beavers at Multiple Spatiotemporal Scales in Desert Rivers.

Front. Conserv. Sci. 3:777797. doi: 10.3389/fcosc.2022.777797

\section{Movement Patterns of Resident and Translocated Beavers at Multiple Spatiotemporal Scales in Desert Rivers}

\author{
Emma Doden 1,2, Phaedra Budy ${ }^{2,3,4}$, Tal Avgar ${ }^{1,2}$ and Julie K. Young ${ }^{1,2,5 *}$ \\ ${ }^{1}$ Department of Wildland Resources, Utah State University, Logan, UT, United States, ${ }^{2}$ The Ecology Center, Utah State \\ University, Logan, UT, United States, ${ }^{3}$ U.S. Geological Survey, Utah Cooperative Fish and Wildlife Research Unit, Utah State \\ University, Logan, UT, United States, ${ }^{4}$ Department of Watershed Sciences, Utah State University, Logan, UT, United States, \\ ${ }^{5}$ Predator Research Facility, USDA National Wildlife Research Center, Millville, UT, United States
}

Wildlife translocations alter animal movement behavior, so identifying common movement patterns post-translocation will help set expectations about animal behavior in subsequent efforts. American and Eurasian beavers (Castor canadensis; Castor fiber) are frequently translocated for reintroductions, to mitigate human-wildlife conflict, and as an ecosystem restoration tool. However, little is known about movement behavior of translocated beavers post-release, especially in desert rivers with patchy and dynamic resources. We identified space-use patterns of beaver movement behavior after translocation. We translocated and monitored nuisance American beavers in desert river restoration sites on the Price and San Rafael Rivers, Utah, USA, and compared their space use to resident beavers after tracking both across 2 years. Resident adult (RA) beavers were detected at a mean maximum distance of $0.86 \pm 0.21$ river kilometers $(\mathrm{km}$; $\pm 1 \mathrm{SE})$, while resident subadult (RS) (11.00 $\pm 4.24 \mathrm{~km})$, translocated adult (TA) (19.69 $\pm 3.76 \mathrm{~km})$, and translocated subadult (TS) $(21.09 \pm 5.54 \mathrm{~km})$ beavers were detected at substantially greater maximum distances. Based on coarse-scale movement models, translocated and RS beavers moved substantially farther from release sites and faster than RA beavers up to 6 months post-release. In contrast, fine-scale movement models using 5-min location intervals showed similar median distance traveled between RA and translocated beavers. Our findings suggest day-to-day activities, such as foraging and resting, were largely unaltered by translocation, but translocated beavers exhibited coarse-scale movement behavior most similar to dispersal by RSs. Coarse-scale movement rates decreased with time since release, suggesting that translocated beavers adjusted to the novel environment over time and eventually settled into a home range similar to RA beavers. Understanding translocated beaver movement behavior in response to a novel desert system can help future beaver-assisted restoration efforts to identify appropriate release sites and strategies.

Keywords: beaver, Castor canadensis, translocation, movement behavior, spatial ecology, post-release movement, net displacement 


\section{INTRODUCTION}

Animal movement behaviors, such as natal dispersal, migration, and territoriality, are important components in the life history and ecological interactions of a species (Nathan, 2008). However, when animals undergo involuntary movement such as translocation to an unfamiliar, novel area, their natural movement behavior can be substantially altered (Heidinger et al., 2009; Le Gouar et al., 2012). Some individuals may exhibit homing behavior, even when released extremely long distances from their place of origin (Dickens et al., 2010). Translocated individuals may be forced to settle in lower-quality habitats (Burns, 2005), disperse if territorial resident conspecifics already occupy high-quality habitat (McNicol et al., 2020), or move away from their release sites in search of mates (Mihoub et al., 2011). In addition, animals may be translocated in response to humanwildlife conflict, but they can again become problem individuals if released in an area that is too small to account for long-range movements or has inadequate resources (Weilenmann et al., 2010; Le Gouar et al., 2012). Difficulties with animal behavior post-translocation, primarily movement or dispersal activities, are some of the most common obstacles to translocation success (Berger-Tal et al., 2020). Therefore, identifying movement patterns post-translocation can help to set expectations and anticipate behavioral responses in future translocation efforts, and ultimately guide conservation and management.

Beaver (American beaver, Castor canadensis, and Eurasian beaver, C. fiber) translocation is a popular method of humanwildlife conflict mitigation and ecosystem restoration. Once overexploited during the fur trade of the 1700s and 1800s (Baker and Hill, 2003; Halley et al., 2021), beaver populations have now recovered in some areas and come in close contact with humans, sometimes causing unwanted flooding, damaging trees, and jeopardizing infrastructure. Translocation provides an alternative method to lethal control by removing beavers from conflict situations and allowing them the opportunity to play a critical role in restoration initiatives. American and Eurasian beavers are ecologically similar (Rosell et al., 2005), and as ecosystem engineers, both species can significantly alter the system they inhabit, primarily through dam building (Mills et al., 1993; Larsen et al., 2021). Beaver dams retain water and mitigate the effects of drought, add heterogeneity to stream channels, impact riparian vegetation, and benefit many other species (Naiman et al., 1988; Rosell et al., 2005; Pollock et al., 2014). However, retaining translocated beavers at a targeted site and encouraging the initiation of passive restoration through dam-building can be challenging, and translocated individuals may not behave similarly to naturally occurring, dam-building beavers, at least initially (Pilliod et al., 2018; Nash et al., 2021).

Beavers are central-place foragers, and dams are most commonly built by territorial colonies to create pools as cover near their lodge or burrow for predator avoidance and transport of wood; beavers rarely build dams during natal dispersal or transience (DeStefano et al., 2006; McClintic et al., 2014b; Ritter, 2018). The home range of established beavers typically covers 1.6-3.9 river kilometers (Breck et al., 2001; Herr and Rosell, 2004; Havens et al., 2013), while dispersing subadult beavers typically travel $3.5-19.8 \mathrm{~km}$ before settling (Beer, 1955; Sun et al., 2000; Ritter, 2018). Autonomous displacement recorded for translocated beavers ranges widely from 3.3 to $238 \mathrm{~km}$, leading to variable dam-building success post-translocation (Hibbard, 1958; McKinstry and Anderson, 2002; Petro et al., 2015).

Beavers can play a vital role in desert rivers, sustaining water and increasing habitat complexity with their dams, especially because many arid systems have become imperiled by altered flow regimes and drought, habitat simplification, invasive species, and climate change (Harper, 2001; Stromberg, 2001; Mott Lacroix et al., 2017). However, the ecology of naturally occurring (hereafter, resident) beavers is understudied in desert rivers, and few translocation studies have been conducted in such systems (Gibson and Olden, 2014; Barela and Frey, 2016). Further, post-release movement behavior of translocated beavers, into a novel degraded desert river where resources may be more patchy, scarce, and unpredictable, may be different from other environments where the majority of beaver studies have occurred (Gibson and Olden, 2014; Barela and Frey, 2016).

We investigated the post-release movements of translocated American beavers (hereafter, beavers) on multiple spatiotemporal scales for 6 months post-release, using resident beavers for baseline comparison of movement behavior. We hypothesized that, at a landscape scale, translocated beavers would initially move farther and more quickly than resident adult (RA) beavers, similar to subadult beavers during dispersal. Farther and faster movement of translocated beavers was expected since they would likely be exploring their novel environment, potentially searching for a mate and a suitable site to settle, whereas RA beavers have established territories and would not need to move as far or as quickly. We also hypothesized translocated beavers would initially be more active than adult resident beavers on a fine-scale (1-h sampling sessions), continuously exploring their new environment, leading to faster movement speeds. In contrast, resident beavers using a familiar territory with set activity patterns would result in slower movement speeds. Our final hypothesis is that after establishing territories, translocated beavers would eventually settle into similar fine- and coarse-scale movement patterns that are similar to territorial adult resident beavers. A better understanding of the movement patterns of translocated beavers in this novel system can help develop an expectation framework of beaver movement behavior for future beaver-assisted restoration efforts in desert systems.

\section{MATERIALS AND METHODS}

\section{Study Area}

We conducted our study in desert tributaries of the Green River, along the lower stretches of the Price River and San Rafael River in east-central Utah, USA. Simplification, aggradation, dewatering, and invasive species encroachment have degraded the lower reaches of these rivers (Walker and Hudson, 2004; Bottcher, 2009). A multi-agency collaborative partnership had previously selected certain sections of these rivers for restoration, hereafter called "targeted restoration sites." On the Price River near Woodside, UT, USA, a $20.5-\mathrm{km}$ stretch of river was identified as a targeted restoration site, and on the San 
Rafael River near Moonshine Wash, an 8.1-km stretch of river was identified as a targeted restoration site. Invasive tamarisk removal, gravel bar additions, native tree planting, and beaver dam analog (BDA) construction had been completed at Moonshine Wash, with beaver translocations included as a passive restoration technique at both sites (Laub, 2015, 2018). Dams built by translocated beavers were intended to supplement the dam-building activity of existing resident beavers as part of the restoration efforts, with the primary objective being to create complex habitat for federally endangered and regionally sensitive endemic fish species such as the Colorado pikeminnow (Ptychocheilus lucius), bonytail chub (Gila elegans), razorback sucker (Xyrauchen texanus), bluehead sucker (Catostomus discobolus), flannelmouth sucker (Catostomus latipinnis), and roundtail chub (Gila robusta; Bottcher et al., 2013; Budy et al., 2015).

We also selected a third field site, a $1.5-\mathrm{km}$ stretch near Cottonwood Wash on the San Rafael River, because it was a unique, complex stretch of river with high habitat suitability for the desert fish species listed above (Bottcher, 2009). This complex reach developed after a sediment plug in 2010 slowly formed a shallow, braided system in the otherwise simplified and degraded river (Lyster, 2018). A resident beaver colony was already established and active there, maintaining and extending complex fish habitat, so we did not translocate any beavers to this site but used it to study resident beaver movement patterns.

Both rivers flow through red rock desert, canyonlands, and desert shrubland. Willow (Salix spp.), Fremont cottonwood (Populus fremontii), common reed (Phragmites spp.), and non-native and invasive tamarisk (live and dead; Tamarix ramosissima), and Russian olive (Elaeagnus angustifolia) make up the majority of riparian vegetation, with cattails (Typha spp.) also growing at Cottonwood Wash. Typical temperatures range from $37^{\circ} \mathrm{C}$ in the summer to $-11^{\circ} \mathrm{C}$ in the winter, and there is little rainfall, averaging $21 \mathrm{~cm}$ per year (National Oceanic Atmospheric Administration, 2021).

To determine existing resident beaver presence before translocations, we conducted sign surveys at Cottonwood and Moonshine Wash in June 2019 and along the Price River in August 2019. Surveys entailed walking, wading, or floating along the rivers and marking all lodges, burrows, dams, and fresh beaver sign such as foraging, slides, and scent mounds on a handheld GPS unit (Garmin, Chicago, Illinois, USA; Model GPSMAP 78s or 66st). We observed evidence of resident beaver activity at Cottonwood Wash and in several stretches of the Price River, but no fresh activity at Moonshine Wash.

\section{Capture, Quarantine, Tagging, and Release}

All procedures including animal capture, handling, tagging, and monitoring were approved by Institute for Animal Care and Use Committees at Utah State University (No.10128) and USDANational Wildlife Research Center (QA-3171). We responded to calls to capture nuisance beavers in northern, central, and eastern Utah for our translocation efforts; these beavers would have been euthanized if not captured and translocated. We captured resident beavers along the Price River and at Cottonwood Wash. We captured translocated and resident beavers from May to
October of 2019 and 2020 using Hancock/Koro suitcase-style traps, Comstock box traps, and non-lethal cable restraints. To accommodate quarantine protocols (Utah Division of Wildlife Resources, 2017; Pilliod et al., 2018), we held translocated beavers for at least 3 days at the Utah State University Beaver Ecology and Relocation Center in Logan, Utah, or the field site. Beavers were provided tree cuttings, root vegetables, rodent pellets, and fresh water daily (Campbell-Palmer and Rosell, 2015). They were held an average of $4.4 \pm 1.3$ days (1 Standard Error) before release.

We chemically immobilized beavers with Butorphanol, Azaperone, and Medetomidine, supplemented with oxygen and isoflurane, to process translocated and resident beavers (Roug et al., 2018). During processing, we assigned an age class based on weight and body size (subadult $=1-2$ years, adult $>2$ years; Patric and Webb, 1960) and sexed beavers using anal gland secretion (Schulte et al., 1995; Woodruff and Pollock, 2018). We categorized beavers into four state categories: RA, resident subadult (RS), translocated adult (TA), and translocated subadult (TS). Due to small sample size, we were unable to split state categories by sex. All beavers received a passive integrated transponder- (PIT-) tag (Biomark APT12 tags; Boise, Idaho, USA) inserted in the tail. We also fitted adult and subadult beavers $>9 \mathrm{~kg}$ with tail-mounted transmitters (Rothmeyer et al., 2002; Arjo et al., 2008). Transmitters were either a remotely downloadable store on-board GPS tag (Africa Wildlife Tracking; Rietondale, Pretoria, South Africa) or a VHF modified ear-tag (Advanced Telemetry Systems, Isanti, Minnesota, USA; Model \#M3530). Initially, we secured GPS- and VHF-tags with $19 \mathrm{~mm}$ neoprene and $19 \mathrm{~mm}$ steel washers, then to improve transmitter retention we increased the sizes of washers to $38.1 \mathrm{~mm}$ neoprene and $31.8 \mathrm{~mm}$ steel washers in September 2019 (Windels and Belant, 2016). Resident beavers were released at their capture sites, while translocated beavers were released at unoccupied stretches of the Price River restoration site and Moonshine Wash study site on the San Rafael River.

\section{Monitoring}

We tracked beavers 2-7 times per week via GPS locations and radio-telemetry using homing-in or triangulation techniques from May through October in 2019 and 2020. To generate beaver locations from triangulations, we input at least three telemetry azimuths $\leq 30 \mathrm{~min}$ apart into "Location of A Signal" (LOAS, version 4.0, Ecological Software Solutions, Sacramento, CA) using Maximum Likelihood Estimation. We only included LOAS locations $<200 \mathrm{~m}$ from the river with $<10$ ha error ellipse in analyses. We also used semi-permanent and submersible passive integrated antennae (PIAs; Biomark; Boise, Idaho, USA) in the rivers to passively detect PIT-tags from May 2019 through March 2021. Some beavers emigrated from the targeted restoration sites, so we scanned along the Green River monthly, conducted one aerial flight, and floated the Price and San Rafael Rivers several times to attempt to locate these individuals. We only included live detections in analyses and assumed that all PIA detections were of live beavers.

We determined transient (temporary) and permanent settlement sites of translocated beavers, which we defined as areas with $\geq 3$ consecutive locations within $0.86 \mathrm{~km}$ (the mean 
TABLE 1 | Types of location data used in models of beaver movement, collected from May 2019 to March 2021 in desert rivers in east-central Utah, USA.

\begin{tabular}{|c|c|c|c|c|c|}
\hline Data type & $\begin{array}{l}\text { Error associated with } \\
\text { data ( } \bar{x} \pm 1 \text { standard } \\
\text { error })\end{array}$ & $\begin{array}{l}\text { Proportion of data in } \\
\text { MDD modeling }\end{array}$ & $\begin{array}{l}\text { Proportion of data in } \\
\text { DR modeling }\end{array}$ & $\begin{array}{l}\text { Proportion of data in } \\
\text { SL modeling }\end{array}$ & $\begin{array}{l}\text { Proportion of data in } \\
\text { FS modeling }\end{array}$ \\
\hline $\begin{array}{l}\text { Passive integrated antennae } \\
\text { detection }\end{array}$ & $0 \mathrm{~m}^{2}$ & 0.45 & 0.60 & 0.30 & - \\
\hline GPS location & $34.3 \pm 2.3 \mathrm{~m}^{2}$ & 0.03 & 0.05 & 0.09 & - \\
\hline Telemetry-homing location & $0 \mathrm{~m}^{2}$ & 0.12 & 0.14 & 0.21 & - \\
\hline Telemetry－triangulation & $3055.8 \pm 651.9 \mathrm{~m}^{2}$ & 0.26 & 0.21 & 0.40 & - \\
\hline Single azimuth intersecting river & $17.8 \pm 1.5 \mathrm{~m}^{2 \mathrm{c}}$ & - & - & - & 1.00 \\
\hline
\end{tabular}

maximum river distance detected for our resident beavers), used for $\geq 7$ days for transient sites, and $\geq 91$ days ( 3 months) for permanent sites (similar to methods in Woodford et al., 2013; Matykiewicz et al., 2021). Time to permanent settlement was recorded as the time an individual was released subtracted from the first time an individual was encountered at its permanent settlement site.

We also conducted hour-long, fine-scale movement monitoring sessions on a weekly to bi-monthly basis per individual. First, we triangulated the location of each beaver to get a general location and position ourselves perpendicular to that point along the river. From this location, we took an azimuth every $5 \mathrm{~min}$ to approximate movement patterns in the river. Depending on terrain and vegetation, we were $10-320 \mathrm{~m}$ from the river during monitoring sessions. All data are reported as $\bar{x} \pm 1$ Standard Error.

\section{Coarse-Scale Movement Analysis}

We used three methods to compare coarse-scale movement patterns among translocated and resident beavers and test our hypotheses. We used all locations $\geq 2.5 \mathrm{~h}$ apart for these analyses (Table 1). First, we used package "riverdist" in Program R for these analyses (Tyers, 2016, version 0.15.3; R Core Team, version $4.0 .3,2020)$. We snapped the most upstream and downstream locations for each beaver to the closest vertex (spaced $0.5 \mathrm{~m}$ apart) of our river network shapefile and calculate the maximum distance detected (in $\mathrm{km}$ ) for all resident and translocated beavers. Second, we calculated the displacement for all beavers, defined as the distance of each beaver location from their release site (in kilometers), only including individuals with $\geq 3$ locations within the first 6 months post-release, as we detected very few individuals longer than this. Third, we calculated the step length (in $\mathrm{m}$ ) between consecutive points.

We constructed a log-linear regression model set comparing ln (maximum distance detected) and beaver state category (RA, RS, TA, TS) in order to analyze maximum observed river distance. For the latter two measurements (translocated beavers), we constructed two log-log linear regression mixed-model sets to assess differences in displacement from release (distance from release $\sim$ time since release) and the distance from one observed location to the next (step length $\sim$ step duration) between resident and TA and subadult beavers, and the influence of several covariates on these differences (Table 2). The log-log regressions are necessary to account for the theoretically expected non-linear relationship between displacement and time (for further details see Street et al., 2018). Individual beaver ID was included as a random effect on both the intercept and $\ln$ (time since release) or $\ln$ (step duration). In the step-length model, we included only step lengths $>0 \mathrm{~m}$, step durations $\leq 60.8$-day ( 2 months), and individuals with $\geq 2$ steps.

We categorized discharge [high, medium, or low; cubic feet per second (cfs)] based on median historical average discharge $(87.2 \mathrm{cfs})$ for the lower Price and San Rafael Rivers, using 66 and 84 years of data, respectively (United States Geological Survey, 2021a). We included all discharges from 0 to $30.9 \mathrm{cfs}$ in the low category, discharges from 31.0 to $142.9 \mathrm{cfs}$ in the medium category, and all discharges $>143.0 \mathrm{cfs}$ in the high category.

We used NDVI as a greenness index of standing plant biomass at beaver locations (Pettorelli et al., 2011; Neumann et al., 2015). NDVI can be used as a measure of suitable beaver habitat because tamarisk thickets and desert habitat have lower NDVI than cottonwood, willow, and riparian zones favored by beavers (Lesica and Miles, 2004; Nagler et al., 2004; Barela and Frey, 2016). Over 95\% of beaver locations used in analyses had a location error $<900 \mathrm{~m}^{2}$, so we downloaded $30 \times 30 \mathrm{~m}$ resolution Landsat 8 Operational Land Imager Surface Reflectance scenes with $<15 \%$ cloud cover for NDVI derivation. We ordered scenes through USGS Earth Explorer (United States Geological Survey, 2021b; https://earthexplorer. usgs.gov/) and NDVI calculations from the Earth Science Processing Architecture platform (United States Geological Survey, 2017; https://espa.cr.usgs.gov/). We generated seasonal mean NDVI pixel values using the "Mosaic to New Raster" tool in ArcGIS Pro (Environmental Systems Research Institute, 2021; version 2.8.0; Redlands, CA, USA). In our rivers, discharge and NDVI typically follow seasonal patterns, so we did not include season as an additional covariate.

We fitted the maximum distance model using the " $1 \mathrm{~m}$ " function in base R (R Development Core Team, 2020; version 4.1.0), while we fitted the displacement and step length models 
TABLE 2 | Key to parameters included in four models of resident adult, resident subadult, translocated adult, and translocated subadult beaver space use.

\begin{tabular}{|c|c|c|c|c|c|}
\hline Parameter & $\begin{array}{l}\text { Parameter } \\
\text { code }\end{array}$ & $\begin{array}{l}\text { Included in } \\
\text { MDD modeling }\end{array}$ & $\begin{array}{l}\text { Included in } \\
\text { DR modeling }\end{array}$ & $\begin{array}{l}\text { Included in } \\
\text { SL modeling }\end{array}$ & $\begin{array}{l}\text { Included in } \\
\text { FS modeling }\end{array}$ \\
\hline Maximum distance detected & $\mathrm{MDD}^{\mathrm{a}}$ & $x$ & & & \\
\hline Displacement from release site & $\mathrm{DR}^{\mathrm{a}}$ & & $x$ & & \\
\hline Step length & $S L^{a}$ & & & $x$ & \\
\hline Median 5 min displacement & $\mathrm{MD}^{\mathrm{a}}$ & & & & $x$ \\
\hline Individual beaver ID & $i$ & & $x$ & $x$ & $x$ \\
\hline State category (Resident adult) & RA & $x$ & $x$ & X & $X$ \\
\hline State category (Resident subadult) & RS & $x$ & $x$ & $x$ & \\
\hline State category (Translocated adult) & TA & $x$ & $x$ & $x$ & $x$ \\
\hline State category (Translocated subadult) & TS & $x$ & $x$ & $x$ & $x$ \\
\hline Step duration & $\mathrm{SD}$ & & & $x$ & \\
\hline Time since release & TR & & $x$ & $X^{c}$ & \\
\hline Is PIA detection & $\mathrm{PIA}$ & & & $x$ & \\
\hline River discharge (low discharge) & LD & & & $x$ & \\
\hline River discharge (medium discharge) & MD & & & $x$ & \\
\hline River discharge (high discharge) & $H D$ & & & $X$ & \\
\hline Normalized Difference Vegetation Index & NDVI & & & $X^{c, d}$ & \\
\hline Time of day (night) & $N$ & & & & $x$ \\
\hline
\end{tabular}

Beavers were monitored via PIT-, VHF-, and GPS-tags in desert rivers in east-central Utah, USA, from May 2019 to March 2021. Models were fitted to each of four response variables: (1) maximum distance detected (MDD; distance between the most upstream and downstream locations of each beaver, in river $\mathrm{km}$; $n=53$ ), (2) displacement (DR; distance from release, in river $\mathrm{km} ; n=1,110)$, (3) step length (SL; distance from one observed location to the next, in river $m$; $n=600$ ), and (4) fine-scale movement rate (FS; median 5-min step length, in river $m ; n=68$ ).

${ }^{a}$ Response variable.

${ }^{b}$ Random effect.

'Scaled and centered.

${ }^{d}$ Start of step.

using package "nlme" in program R (Pinheiro et al., 2013; version 3.1.152). We constructed models for the three coarsescale movement metrics using several covariates (Table 2). We confirmed normality using diagnostic plots of the best model residuals.

\section{Fine-Scale Movement Analysis}

We estimated the location of each beaver in the river using the "Bearing Distance to Line" and "Intersect" tools in ArcGIS Pro (Environmental Systems Research Institute, 2021; version 2.8.0; Redlands, CA, USA) from the azimuths taken during fine-scale ( 5 min between consecutive observations) movement monitoring sessions (Table 1). We assumed beavers were in the river for all locations. Using these estimated points, we calculated the step length between consecutive points in "riverdist" using the same methods as described above. Lastly, we calculated the median 5-min step length (in $\mathrm{m}$ ) for each sampling session. We were unable to include all 5-min step lengths within all sampling sessions because our sample size was too small to include nested random effects of sampling session within individual beaver ID. In addition, we did not detect any RSs long enough to conduct these fine-scale movement monitoring sessions, and we excluded Cottonwood Wash from this analysis because we only monitored one individual at a fine-scale in this site. High median distance moved was an indicator of an active beaver, perhaps out foraging, while a low median distance moved likely indicated an inactive beaver, likely resting.
We used a log-linear regression mixed model to compare the fine-scale movement rates (median 5-min step lengths) of RA, TAs, and subadult beavers, and the influence of several covariates on these movement patterns (Table 2). We categorized daytime as 06:00-17:59 $\mathrm{h}$ and nighttime as 18:00-05:59 h. We fitted the fine-scale movement rate model using package "nlme" in program $\mathrm{R}$ (Pinheiro et al., 2013; version 3.1.152). We used residual diagnostic plots to confirm normality.

\section{RESULTS}

We captured and PIT-tagged 41 translocated beavers and fit 35 translocated beavers ( 21 adults, 14 subadults) with radio transmitters. We PIT-tagged 16 resident beavers and fit 12 resident beavers with radio transmitters ( 9 adults, 3 subadults). We censored three additional resident beavers from analyses because they died from capture- or processing-related events. We released resident beavers at their capture sites, at Cottonwood Wash $(2019 ; n=3,2$ adults and 1 subadult) and in the Price River (2019 and 2020; $n=13,8$ adults and 5 subadults). We released 36 translocated beavers $(76.5 \%)$ as family groups or as pairs formed during quarantine. We released 33 translocated beavers (16 adults and 17 subadults) in unoccupied portions of the Price River targeted restoration site both years, but only released 8 translocated beavers ( 5 adults and 3 subadults) near BDAs at Moonshine Wash in 2019. Drought in 2020 caused extremely low 
TABLE 3 | Fixed effects estimates from four movement models of resident adult $(R A)$, resident subadult $(R S)$, translocated adult $(T A)$, and translocated subadult (TS) beavers monitored via PIT-, VHF-, and GPS-tags in desert rivers in east-central Utah, USA, from May 2019 to March 2021.

\begin{tabular}{|c|c|c|c|c|}
\hline Parameter & Estimate & Lower $95 \%$ Cl & Upper $95 \%$ Cl & $p$-values \\
\hline \multicolumn{5}{|c|}{ Maximum distance detected } \\
\hline RA & -0.42 & -1.18 & 0.34 & 0.29 \\
\hline RS & 2.12 & 0.98 & 3.26 & $<0.001$ \\
\hline TA & 2.56 & 2.07 & 3.05 & $<0.001$ \\
\hline TS & 2.31 & 1.78 & 2.84 & $<0.001$ \\
\hline \multicolumn{5}{|c|}{ Coarse-scale displacement } \\
\hline RA & 0.30 & -0.21 & 0.81 & 0.26 \\
\hline RS & 0.90 & -0.22 & 2.02 & 0.12 \\
\hline TA & 0.45 & 0.12 & 0.78 & 0.01 \\
\hline TS & 0.59 & 0.22 & 0.96 & $<0.01$ \\
\hline $\mathrm{RA}^{*} \operatorname{Ln}(\mathrm{TR})$ & -0.01 & -0.21 & 0.19 & 0.91 \\
\hline $\mathrm{RS}^{\star} \mathrm{Ln}(\mathrm{TR})$ & 0.52 & 0.01 & 1.03 & 0.05 \\
\hline $\mathrm{TA}^{\star} \operatorname{Ln}(\mathrm{TR})$ & 0.35 & 0.21 & 0.49 & $<0.001$ \\
\hline TS*Ln(TR) & 0.46 & 0.32 & 0.60 & $<0.001$ \\
\hline \multicolumn{5}{|c|}{ Coarse-scale step length } \\
\hline RA & 4.71 & 3.69 & 5.73 & $<0.001$ \\
\hline RS & 7.73 & 5.85 & 9.61 & $<0.001$ \\
\hline TA & 6.61 & 5.67 & 7.55 & $<0.001$ \\
\hline TS & 6.48 & 5.36 & 7.60 & $<0.001$ \\
\hline PIA & 0.42 & 0.03 & 0.81 & 0.03 \\
\hline LD & -0.64 & -1.42 & 0.14 & 0.11 \\
\hline HD & -0.26 & -1.16 & 0.64 & 0.57 \\
\hline NDVI & -0.11 & -0.31 & 0.09 & 0.24 \\
\hline $\mathrm{RA}^{*} \operatorname{Ln}(\mathrm{TR})$ & -0.69 & -1.06 & -0.32 & $<0.001$ \\
\hline $\mathrm{RS}^{*} \operatorname{Ln}(\mathrm{TR})$ & 0.18 & -0.56 & 0.92 & 0.62 \\
\hline $\mathrm{TA}^{\star} \operatorname{Ln}(\mathrm{TR})$ & 0.08 & -0.25 & 0.41 & 0.64 \\
\hline$T S^{*} \operatorname{Ln}(T R)$ & 0.03 & -0.44 & 0.50 & 0.89 \\
\hline $\mathrm{RA}^{*} \mathrm{Ln}(\mathrm{SD})$ & 0.47 & 0.12 & 0.82 & 0.01 \\
\hline$R S^{*} \operatorname{Ln}(S D)$ & -0.13 & -0.99 & 0.73 & 0.78 \\
\hline $\mathrm{TA}^{*} \operatorname{Ln}(\mathrm{SD})$ & 0.61 & 0.30 & 0.92 & $<0.001$ \\
\hline $\mathrm{TS}^{\star} \operatorname{Ln}(\mathrm{SD})$ & 0.47 & 0.02 & 0.92 & 0.04 \\
\hline \multicolumn{5}{|c|}{ Fine-scale movement rate } \\
\hline RA & 1.95 & 1.36 & 2.54 & $<0.001$ \\
\hline TA & 1.21 & 0.35 & 2.07 & $<0.01$ \\
\hline TS & 1.45 & 0.88 & 2.02 & $<0.001$ \\
\hline$N$ & 0.89 & 0.34 & 1.44 & $<0.01$ \\
\hline
\end{tabular}

Models were fitted to each of four response variables: (1) maximum distance detected (distance between the most upstream and downstream locations for each beaver, in river $\mathrm{km}$; adjusted $R^{2}=0.78, n=53$ ), (2) displacement (distance from release, in river $\mathrm{km}$; marginal $R^{2}=0.45$, conditional $R^{2}=0.86, n=1,110$ ), (3) step length (distance from one observed location to the next, in river $m$; marginal $R^{2}=0.30$, conditional $R^{2}=0.51, n=$ 600 ), and (4) fine-scale movement rate (median 5-min step length, in river m; marginal $R^{2}$ $=0.20$, conditional $R^{2}=0.28, n=68$ ).

flows in the San Rafael River, resulting in unsuitable conditions for translocation at Moonshine Wash.

We detected RS and translocated beavers over significantly longer stretches of river than RA beavers (Table 3; Figure 1). The average time passed between an individuals' most up- and down-stream locations was $54.1 \pm 31.5$ days for RA beavers,
$35.9 \pm 30.1$ days for RS beavers, $38.1 \pm 23.6$ days for TA beavers, and $40.6 \pm 12.1$ days for TS beavers. We detected $41.4 \%$ of all TA and subadult beavers $(n=17)>20 \mathrm{~km}$ from their release site (Figure 2), and $61.4 \%$ of RS and translocated beavers were downstream of their release site at their final detection (25.0\% of RS, $66.7 \%$ of TA, and $63.2 \%$ of TS). Eleven translocated beavers (four adults at the Price River, two adults at Moonshine Wash, and five subadults at the Price River) settled in transient resting sites within the targeted restoration sites for an average of $16.2 \pm 2.7$ days before moving to other areas. We did not observe any transient resting sites for RS beavers. Four translocated beavers (two adults, two subadults) permanently settled outside the targeted restoration sites 8.6-155.4 days after release $(72.2 \pm 34.6$ days); three near the confluence of the Green and Price Rivers, and one subadult beaver farther downstream, near the town of Green River. We detected these beavers for an average of $134.8 \pm 7.5$ days with PIAs at these settlement sites.

Based on the displacement model, we observed distinct differences between RA beavers and RS or translocated beavers in the relationship between the distance traveled from their release sites and time (Table 3; Figure 3). For RAs, $\ln$ (time since release) had no detectable effect on $\ln$ (distance from release)RA beavers did not change their displacement from their release site over time. In contrast, translocated beavers and RS beavers moved farther from their release sites during the monitoring period, albeit at a diminishing rate (Table 3; Figure 3). The random effects of Beaver ID on both the intercept and the effect of $\ln$ (time since release) substantially improved model fit [likelihood-ratio $\chi_{(2, n=1,110)}^{2}=225.29, p<0.001 ;$ marginal $R^{2}=$ 0.45 , conditional $\left.R^{2}=0.86\right]$.

Based on the step-length model, we observed differences between the displacement rates of RA beavers and RS or translocated beavers (Table 3). Passive integrated antennae detections were associated with higher displacement rates, while neither river discharge category nor NDVI value at the start of a step affected displacement rates in the model. Resident adult beavers moved more slowly than the beavers in other state categories, although the confidence intervals of all state categories overlapped to some extent (Figure 4). When all other covariates were held constant, RA, and translocated beavers exhibited acceleration initially, followed later by gradual deceleration in increasing step duration. Resident subadult beavers exhibited quick deceleration initially, followed later by gradual deceleration in increasing step duration (Figure 4). Resident subadult beavers displaced fastest over short time periods (i.e., hours and days), while translocated beavers displaced fastest over long time periods (i.e., months, Figures 4, 5). Resident adult beavers moved the slowest at all temporal scales (Figure 5). Resident adults also reduced their speed as time since release increased, whereas the three other beaver state categories demonstrated a slight increase in speed as time since release increased (Figure 5). Similar to the displacement model, the random effects of Beaver ID on both the intercept and the effect of $\ln$ (step duration) substantially improved model fit [likelihood-ratio $\chi_{(2, n=600)}^{2}=11.66, p<0.01$; marginal $R^{2}=0.30$, conditional $\left.R^{2}=0.51\right]$. 


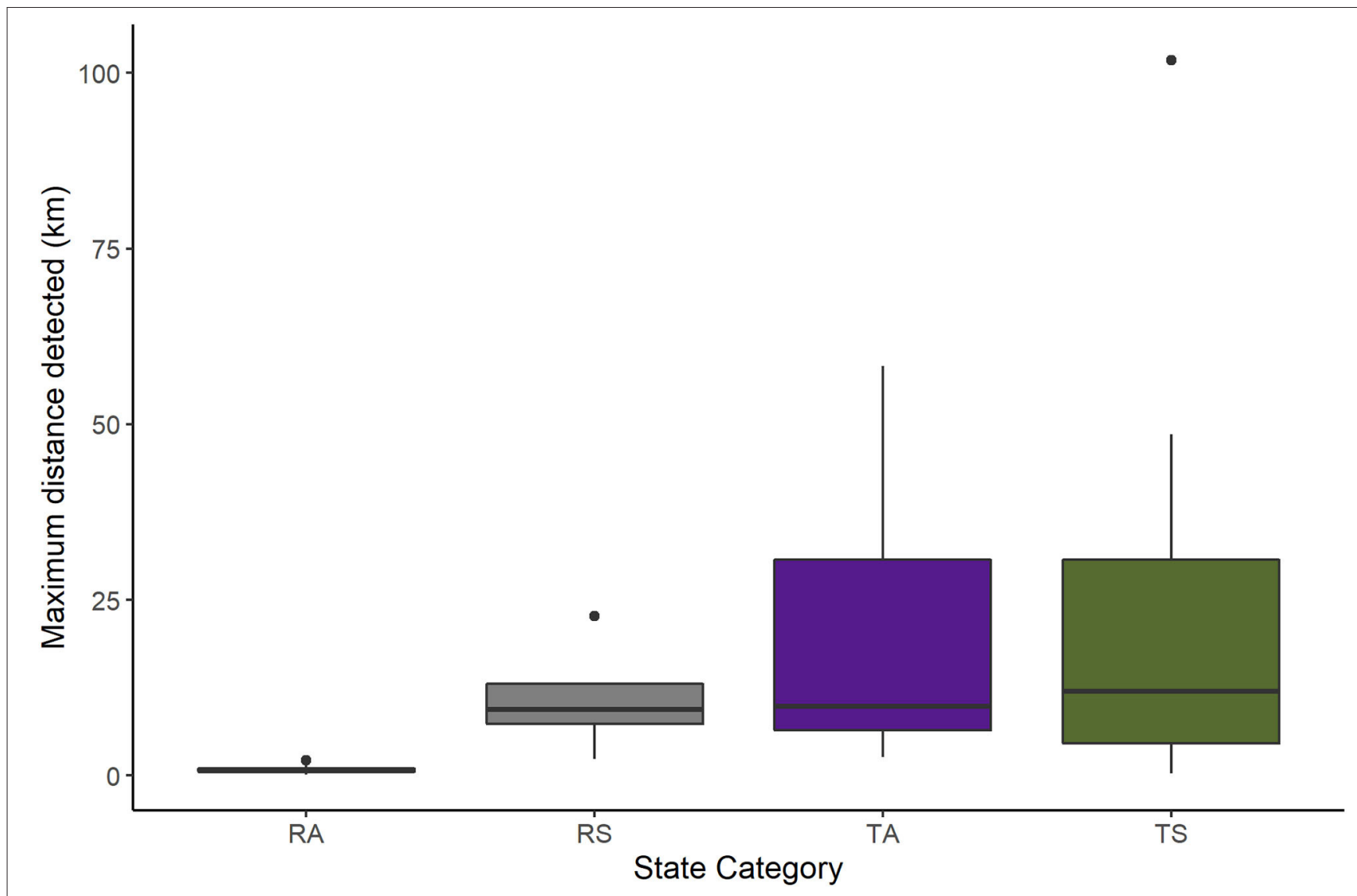

FIGURE 1 | The maximum distance between the most upstream and downstream locations resident adult (RA, $n=9$ ), resident subadult (RS, $n=4)$, translocated adult (TA, $n=21$ ), and translocated subadult (TS, $n=19)$ beavers were detected $(\mathrm{km})$ in the Price, San Rafael, and Green Rivers in east-central Utah, USA. Beavers were monitored via PIT-, VHF-, and GPS-tags from May 2019 to March 2020. The boxes encompass the first through third quartiles (25-75 percentiles), while the whiskers extend to the highest or lowest values within 1.5 times the inter-quartile range (the distance between the first and third quartiles). Maximum distances detected outside of this range are outliers and plotted as points.

The fine-scale movement rates of RA and translocated beavers were similar (Table 3; Figure 6). Time of day (i.e., day vs. night) was an important parameter explaining fine-scale beaver movement patterns, with beavers being more active at night. Including a random effect of Beaver ID on the intercept in the fine-scale movement rate model did not improve model fit [likelihood ratio $\chi_{(1, n=1,110)}^{2}=0.28, p=0.6$; marginal $R^{2}=0.20$, conditional $R^{2}=0.28$ ], but was necessary to account for the repeated sampling events for individual beavers.

\section{DISCUSSION}

Our findings suggest translocated beavers exhibited movement behavior similar to dispersing RS beavers, likely moving through their new environment in search of a mate and a suitable site to settle. We found that translocated beavers demonstrated movement patterns similar to RS beavers in the first 6 months post-release, with an exploratory dispersive phase following release gradually decaying into more sedentary space-use indicative of home range establishment. Translocated beavers moved substantially farther and faster than RA beavers, beavers which already had established territories and therefore likely had no need for such exploratory movement patterns. However, contrary to our fine-scale movement rate hypothesis, we observed no differences in median distance moved between translocated and RA beavers over a short time span (5 min), suggesting day-to-day activity patterns such as foraging and resting were not greatly impacted by dispersal or translocation. These results suggest that although translocated beavers typically demonstrated wide-ranging movement patterns initially, movement behavior patterns will eventually mimic RA beavers.

Resident adult beavers remained in small stretches of river throughout time, with maximum distance detected between the most upstream and downstream locations of each beaver averaging $0.86 \pm 0.21$, suggesting they held established home ranges and territories. The distance we observed was smaller than naturally occurring American and Eurasian beaver home ranges reported in other studies $(3.6 \pm 0.3 \mathrm{~km}$, Graf et al., 2016b; 2.2 $\pm 0.5 \mathrm{~km}$, Breck et al., 2001; $1.8 \pm 0.3 \mathrm{~km}$ in smaller streams and $3.6 \pm 0.5 \mathrm{~km}$ in larger rivers, Havens et al., 2013). Smaller 


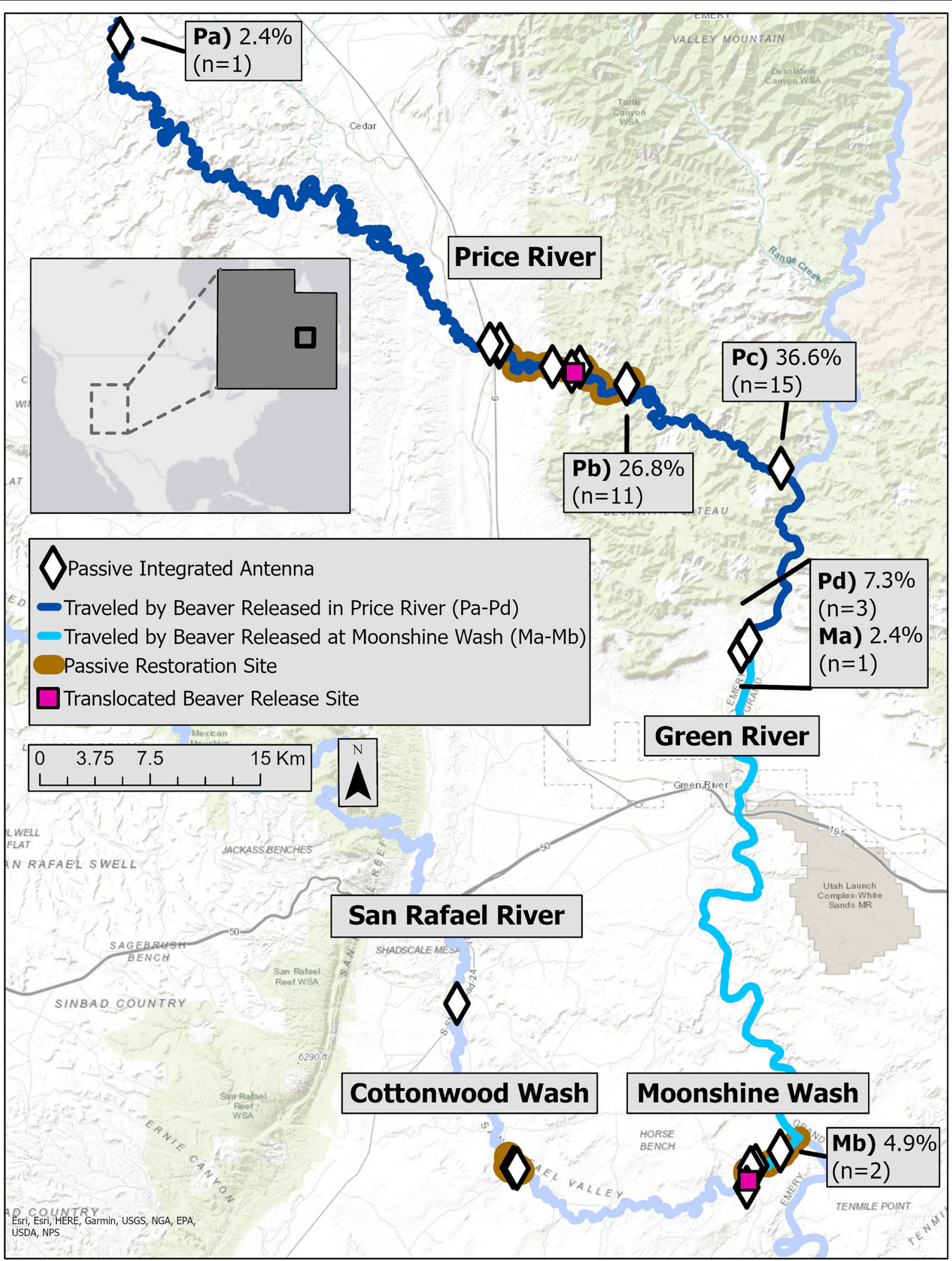

FIGURE 2 | Passive restoration sites and surrounding stretches of river on the Price River and the lower San Rafael River at Cottonwood Wash and Moonshine Wash in east-central Utah, USA. Inset text boxes labeled with letters represent the proportion and number of translocated beavers detected at certain passive integrated 
FIGURE 2 | antennae (PIAs) outside of or near the end of the passive restoration sites. The color of the river line indicates which release site translocated beavers originated from (Moonshine Wash or Price River) ${ }^{\mathrm{a}}$; 36.6\% ( $\left.n=15\right)$ of translocated beavers were not detected by the labeled PIAs (Pa-Pd or Ma-Mb), and $17.1 \%(n=$ 7) of translocated beavers were detected at more than one of the labeled PIAs. ${ }^{a}$ Distance each PIA is from each release site: Pa, $101 \mathrm{~km}$ from Price River release site; $\mathrm{Pb}, 7 \mathrm{~km}$ from Price River release site; Pc, $29 \mathrm{~km}$ from Price River release site; Pd, $47 \mathrm{~km}$ from Price River release site; Ma, $58 \mathrm{~km}$ from Moonshine Wash release site; $\mathrm{Mb}, 5 \mathrm{~km}$ from Moonshine Wash release site.

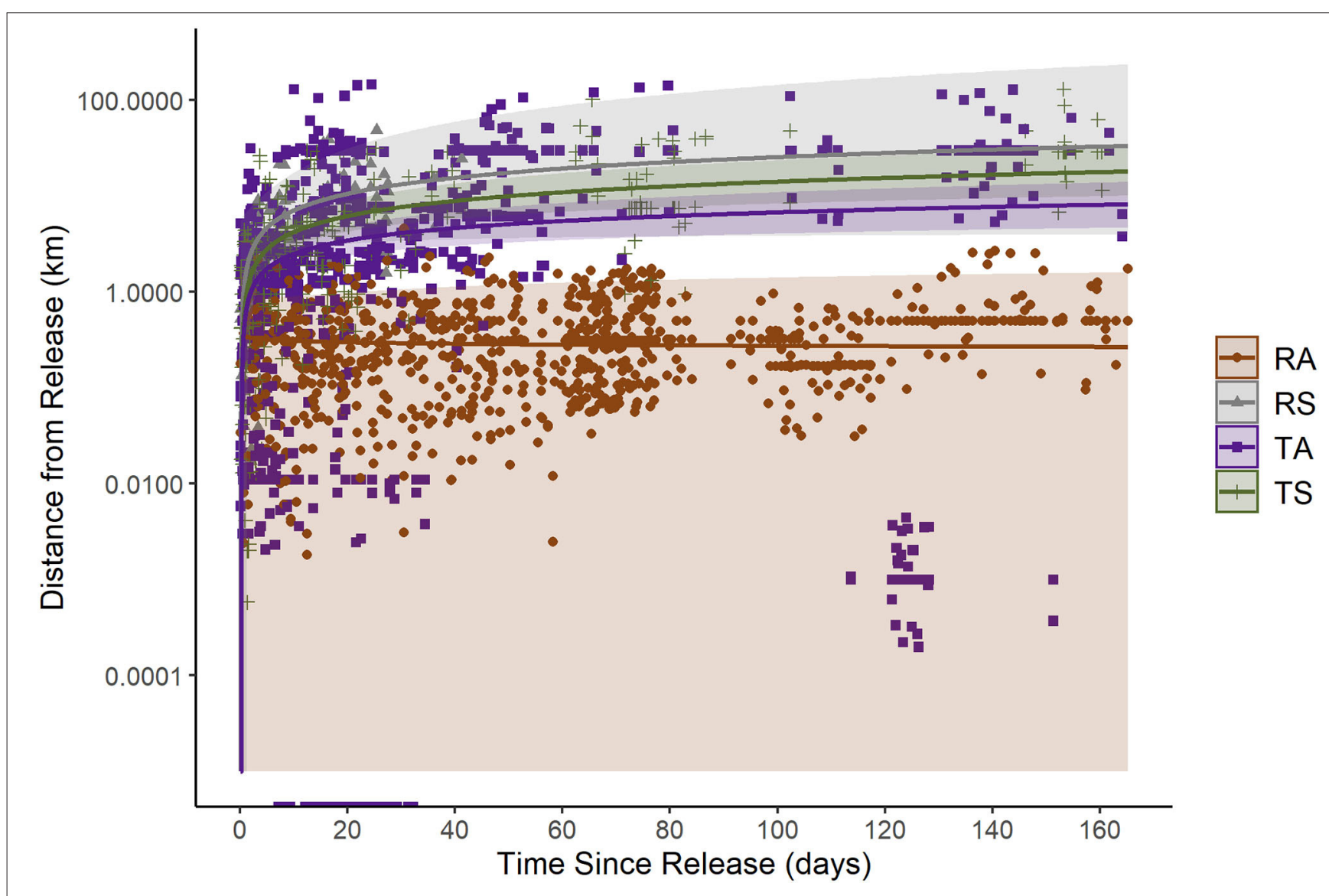

FIGURE 3 | Relationship between distance from release (displacement, in river $\mathrm{km}$ ) and time since release for beavers (RA, resident adult; RS, resident subadult; TA, translocated adult; TS, translocated subadult) monitored in desert rivers, east-central Utah, USA, from May 2019 to March 2021. Lines and shaded 95\% Confidence Intervals only include the fixed effects from the back-transformed predicted values of a log-log regression linear mixed model (marginal $R^{2}=0.45$, conditional $R^{2}=0.86, n=1,110$ ).

home ranges may be caused by resources being less dispersed and less diverse in smaller rivers (Havens et al., 2013). Our findings are consistent with previous findings in smaller streams, such as a small creek in Oregon where mean linear home range size was $1.56 \pm 0.71 \mathrm{~km}$ (1 SE; Maenhout, 2013). Alternatively, home ranges may have been small because seasonal resource availability affects beaver movement (Bloomquist et al., 2012; McClintic et al., 2014a; Korbelová et al., 2016), which may be intensified in a desert ecosystem. Summer temperatures in our study system were extremely high and food resources were often localized; these two factors potentially contribute to reduced movements. In addition, we tracked many beavers during drought periods when river discharges were low, increasing the difficulty for beaver to evade predators when far from the safety of a burrow or lodge.
The maximum distances we detected between the most upstream and downstream locations for each RS were similar to or larger than movement patterns recorded in other studies. In Montana, mean dispersal-settlement distance for subadult American beavers was $10.9 \pm 3.1 \mathrm{~km}$ (Ritter, 2018), and in Oregon, it was $16.2 \pm 9.3 \mathrm{~km}$ (Maenhout, 2013), yet mean dispersal distance of Eurasian beavers in Norway was 4.5 $\pm 5.4 \mathrm{~km}$ (Mayer et al., 2017). The four RS beavers in our study dispersed following release; three moved $>9.0 \mathrm{~km}$. One beaver only moved $2.38 \mathrm{~km}$ from its natal colony to another colony, an indication of successful dispersal (Sun et al., 2000). While it is possible that capture, quarantine, and handling could have induced these dispersal events (e.g., Kukalová et al., 2013), a study in Norway demonstrated no change in shortterm Eurasian beaver space use post-capture and post-tagging, 


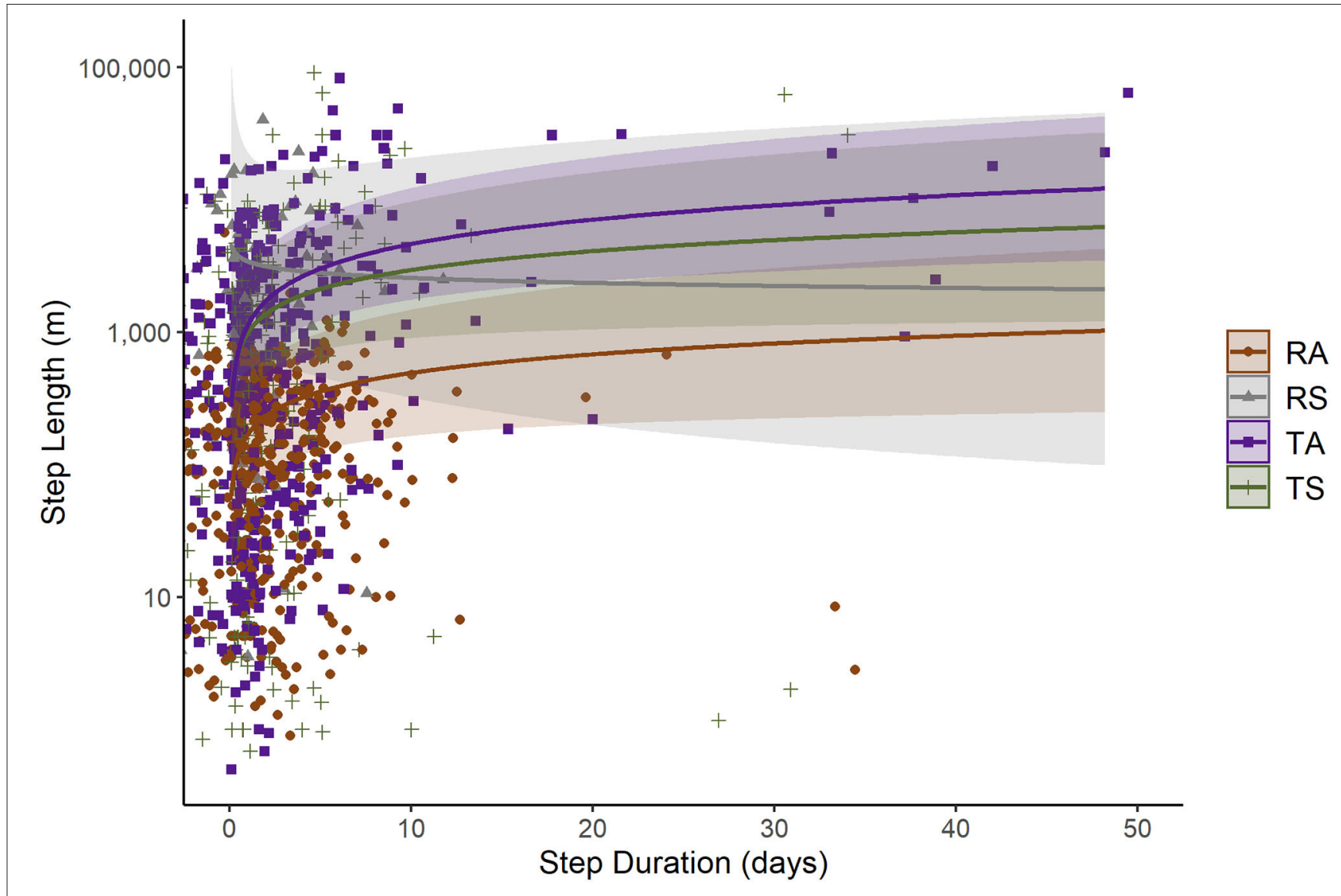

FIGURE 4 | Relationship between step length (in river m) and step duration (in days) for beavers (RA, resident adult; RS, resident subadult; TA, translocated adult; TS, translocated subadult) monitored in desert rivers, east-central Utah, USA, from May 2019 to March 2021. Lines and shaded 95\% Confidence Intervals only include the fixed effects from the back-transformed predicted values of a log-log regression linear mixed model (marginal $R^{2}=0.30$, conditional $R^{2}=0.51, n=600$ ). We held all other covariates included in the model constant for visualization purposes (medium river discharge category only, PIA detections only, mean NDVI value, and mean time since release).

although only dominant adults were included in their study (Graf et al., 2016a).

Similar to other studies, translocated beavers were detected to have moved similar maximum distances as RS beavers. The mean distances moved for beavers translocated in North Dakota was $14.6 \pm 2.1 \mathrm{~km}$ (Hibbard, 1958), 7.4 straight-line $\mathrm{km}$ for beavers translocated to streams in Wisconsin (Knudsen and Hale, 1965), and $>10 \mathrm{~km}$ from their release sites for $51 \%$ of translocated beavers in Wyoming (McKinstry and Anderson, 2002). Conversely, translocated beavers only moved a mean distance of $3.3 \pm 0.2 \mathrm{~km}$ from their release sites in Oregon, indicating their modelbased method of release-site selection may have identified high-quality vacant habitat, encouraging beavers to stay (Petro et al., 2015). Translocated individuals may also roam much farther than naturally dispersing individuals. Along with our study, where translocated beavers moved up to $101.8 \mathrm{~km}$, beavers have been reported to move $238 \mathrm{~km}$ in North Dakota (Hibbard, 1958) and $76.2 \mathrm{~km}$ in Wisconsin (Knudsen and Hale, 1965).
Results of our displacement model showed that RS and translocated beavers moved farther from their release sites than RA beavers. Spatiotemporal autocorrelation may exist due to our use of sequential observations in this model and despite accounting for repeated observations using random effects. Nonetheless, our results serve as an effective demonstration of the considerably larger distances traveled by dispersing subadult and translocated beavers compared to RA beavers, even soon after release. Final detections for $61.4 \%$ of our translocated and RS beavers were downstream of their release sites, similar to previous studies of dispersing subadult beavers that reported that the predominant direction of travel is downstream (Leege, 1968; Sun et al., 2000). Beavers likely exert less energy while covering longer distances when traveling with the current. Results from our displacement model show TA beavers demonstrated lower displacement from release than resident and TS beavers, potentially indicating these individuals settled more quickly, although this result should be interpreted with some caution because the confidence intervals overlapped. Most adult translocated beavers likely 

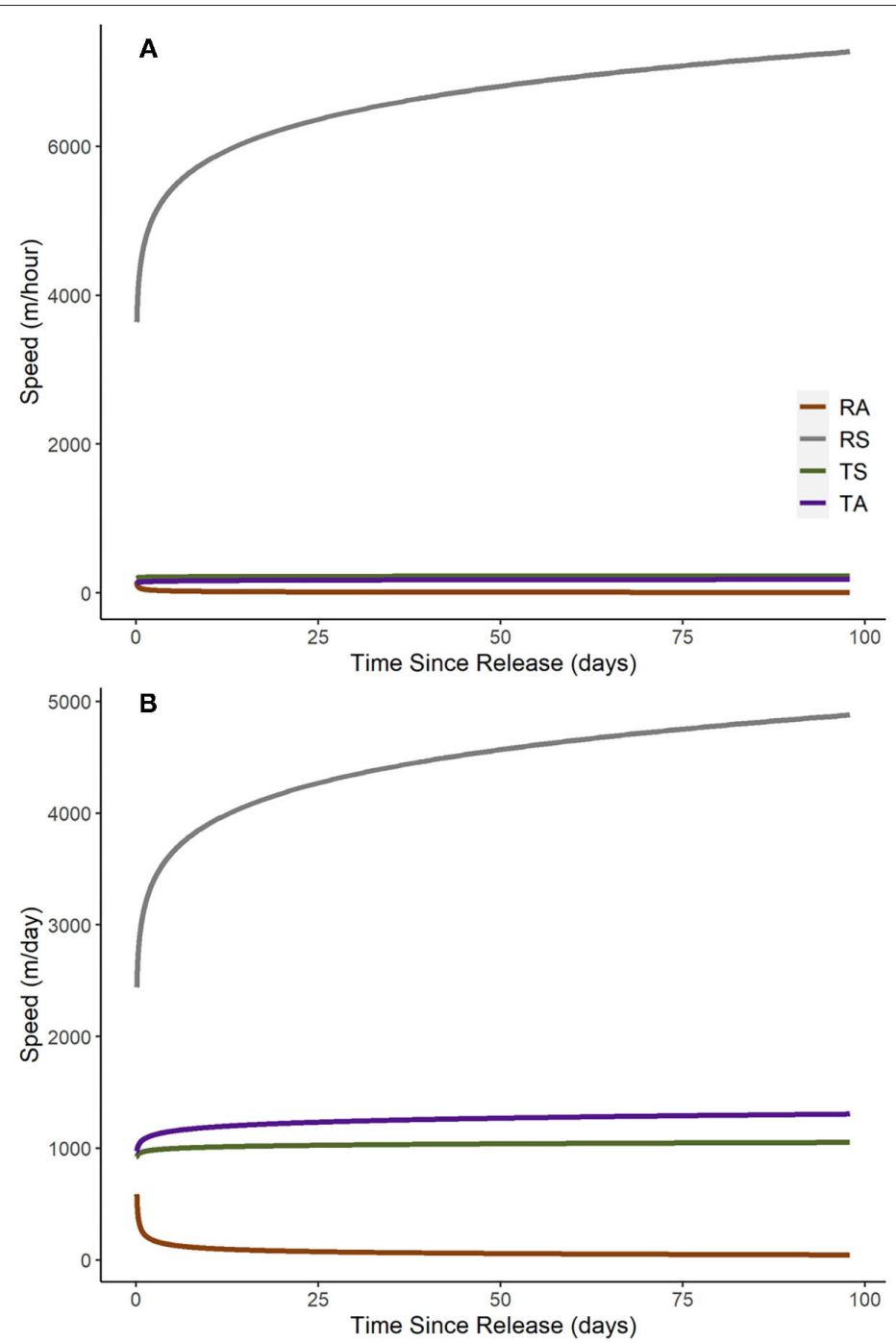

C

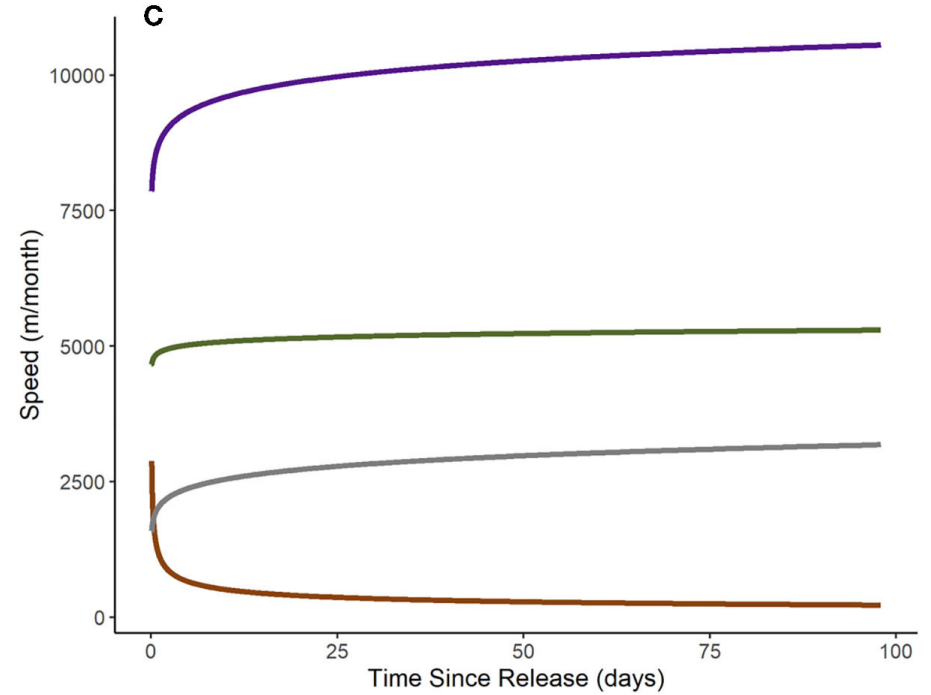

FIGURE 5 | Predicted relationship between speed (step length/step duration) at multiple temporal scales [(A), m/hour; (B), m/day; (C), m/month] and time since release for resident adult (RA), resident subadult (RS), translocated adult (TA), and translocated subadult (TS) beavers monitored in the Price, San Rafael, and Green Rivers, Utah, USA, from May 2019 through March 2021. Relationships are based on a log-log regression linear mixed model. All other covariates included in this model were held constant for visualization purposes (medium river discharge category only, PIA detections only, and mean NDVI value). 


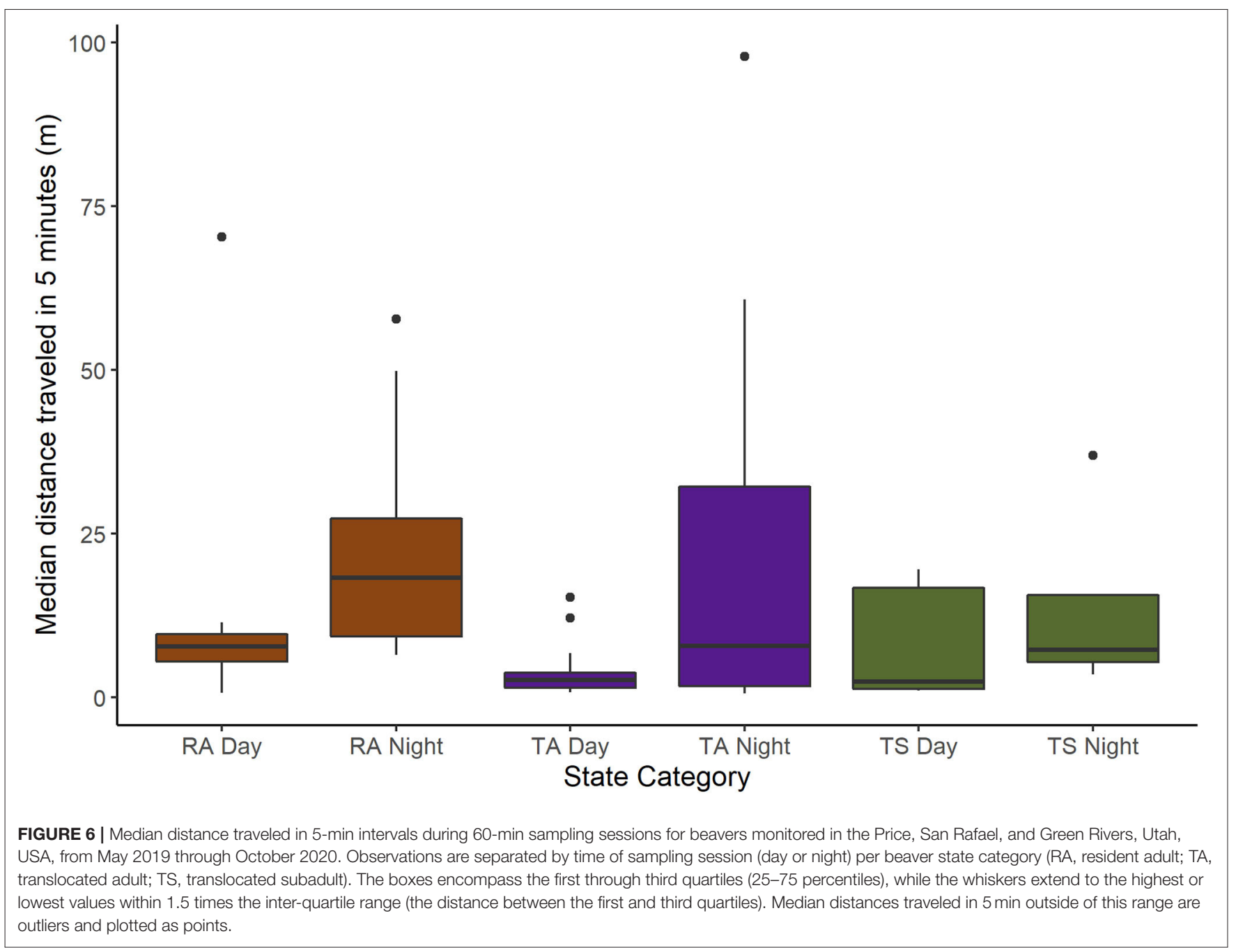

already experienced natal dispersal through an unfamiliar environment and territory establishment in their lifetime (Baker and Hill, 2003). Perhaps this previous experience led them to more quickly settle in the closest suitable site, find a mate, and defend their new territory from subordinate subadult beavers, who may not have dispersed before. Knowledge on previous experience by beavers slated for translocations may be difficult to obtain but could improve which individuals would exhibit philopatry and should be considered in future research.

Dispersing beavers may need to travel longer distances to find an area to settle with sufficient resources for survival in desert rivers because they have patchier and more unpredictable resources (Gibson and Olden, 2014; Barela and Frey, 2016). Rivers in our study had low existing beaver densities (Macfarlane et al., 2017). This may have allowed RS and translocated beavers to be choosier about selecting high-quality sites for settlement because there was reduced "social resistance" effects (Armansin et al., 2020) with more unoccupied territories and less potential for aggressive encounters with conspecifics (DeStefano et al., 2006). Some of our translocated beavers used temporary settlement sites centered around a discovered burrow or hiding place as a known safety refuge from which to conduct exploratory movements; this has been documented in dispersing subadult beavers (Sun et al., 2000; McNew and Woolf, 2005; Ritter, 2018).

When existing resident populations are low, as is common in conservation translocation or reintroduction efforts (Seddon et al., 2014), translocated individuals may have to travel farther to find a mate. One week post-release we observed no translocated beavers who were released as a pair or family group in close proximity to each other, indicating that translocated beavers were likely unable to find their original release groups and instead were searching for new mates. This group fission is similar to a study in Kazakhstan in which translocated kulan (Equus hemionus kulan) had difficulty reconnecting with other translocated individuals once breaking from the group, negatively impacting reproduction in the reintroduced herd (Kaczensky et al., 2021). These findings emphasize the importance of translocating large numbers of individuals or releasing individuals near existing populations to increase 
conspecific encounter rates and increase recruitment, a key to conservation translocation success.

Our results also demonstrated RS and translocated beavers move more quickly than RA beavers, although there was some overlap in confidence intervals. Resident adult beavers were likely already settled in the best quality habitat, spending more time in concentrated areas of high resource availability with a known place of safety nearby, therefore moving more slowly to reduce their encounter rates with predators (Prokopenko et al., 2017; Dickie et al., 2020). Conversely, the fact that RS and translocated beavers were in an unfamiliar, novel environment may have heightened their perceived predation risk, causing them to move faster. Beavers moved faster the farther they were from their lodge to minimize increased predation risk from alligators in less familiar areas of Alabama (McClintic et al., 2014b).

Fine-scale movement behavior did not differ among categories of beaver, suggesting environmental factors had a larger effect on median distance moved over short time periods ( 5 min intervals). In general, beavers exhibit crepuscular or nocturnal activity patterns, a common predator avoidance strategy (Swinnen et al., 2015). Translocation or dispersal did not alter this behavior; all beavers moved less during the day, likely resting in burrows or lodges to insulate against the extreme desert temperatures (Buech et al., 1989). During dispersal or translocation, beavers must still forage and rest to survive, and our fine-scale movement patterns suggest that these short-term behaviors remained similar to RA beavers. We note that there is likely some error in our estimation of the true location of beavers during fine-scale monitoring. We used single azimuths to estimate locations, but the error remained generally the same at various sampling distances from the river based on calibration tests using stationary test transmitters, and among different beaver state categories. As such this bias was fairly uniform across sampling sessions and should not affect relative comparisons.

Inference from our results are somewhat limited due to sample size once individuals were classified among the beaver categories. For example, we did not include sex because it was confounded with other parameters in the models: both male and female beavers are territorial and disperse, so we did not expect sex to have a strong effect on movement as compared to beaver category (Baker and Hill, 2003). Results for RS beavers demonstrated the largest variation and widest confidence intervals of the four beaver categories, likely due to the small sample size of this state category $(n=4)$. In future studies, the use of more detailed habitat covariates or conducting a habitat selection analysis may reveal more about the external drivers of coarse-scale movement behavior in desert systems (e.g., Wang et al., 2019; Ritter et al., 2020). Despite our unsurprisingly low small sample size and thus limited inferential power, the patterns we observed were clear and supported most of our original hypotheses.

In terms of displacement, though translocated beavers tended to move more similarly to dispersing RS beavers overall, we observed a gradual leveling-off of differences among beaver categories, suggesting these individuals will eventually establish a home range similar to RA beavers and may subsequently build dams which contribute to restoration. Logistical challenges limited our monitoring period to 6 months post-release, or shorter periods for some individuals due to transmitter failure (Doden, 2021), so confirming settlement site establishment was challenging. However, we observed four translocated beavers permanently settle outside of the targeted restoration sites 8.6-155.4 days post-release, supporting our expectation that translocated beavers will eventually settle and behave similarly to RA beavers in regard to movement. Indeed, translocated individuals of any species must adjust to their novel environment to survive but need time to learn and explore their new surroundings in order to make appropriate changes to their behavior. For example, translocated "alalā" (Corvus hawaiiensis) in Hawaii learned to be more vigilant over time to limit predation at supplemental feeding sites (Lee et al., 2021), and swift foxes (Vulpes velox) translocated in Canada exhibited distinct postrelease movement stages (initial acclimation, establishment, final settlement) as they adjusted to their new surroundings over time (Moehrenschlager and Macdonald, 2003).

The comparative technique we used here to monitor naturally occurring resident individuals to translocated individuals should inform translocation expectations and outcomes for the conservation of beavers as well as other species. Results from a concurrent study demonstrated that $40.4 \%$ of translocated beavers included in this study were detected outside of targeted restoration sites, while no RA beavers were detected outside of the targeted restoration sites (Doden, 2021). Despite the variable site fidelity of translocated beavers, 22 dams were constructed by resident and translocated beavers in the targeted restoration sites during the study, suggesting that translocations had some success in supplementing resident beaver dam-building and contributing to restoration objectives. Identifying ways to improve the proportion of translocated beavers that settle within targeted restoration sites is an important next step. Previous studies have observed increases in beaver dams near structural features such as BDAs installed in rivers, and these structures create deep pools which may help improve translocation success (Bouwes et al., 2016; Pollock et al., 2018). However, this approach has yet to be studied simultaneously with translocations in desert systems. In addition, even beavers that settled outside of targeted restoration sites should be considered to contribute to restoration success at a more riverscape scale. These desert tributaries have, in some cases $50-100 \mathrm{~km}$ of very degraded habitat, and native fishes are challenged by this flow-related habitat simplification at very large scales (Budy et al., 2015; Pennock et al., 2021). Our study presents novel research critical to informing future beaver translocation efforts in desert rivers, because this study is the first to compare naturally occurring resident beaver movement behavior to translocated beaver movement behavior in the same system and is one of few studies of beaver movement ecology in desert systems (Gibson and Olden, 2014).

\section{DATA AVAILABILITY STATEMENT}

The raw data supporting the conclusions of this article will be made available by the authors, without undue reservation or at Dryad, doi: 10.3389/fcosc.2022.777797 


\section{ETHICS STATEMENT}

All procedures in this study including animal capture, handling, tagging, and monitoring were approved the Institute for Animal Care and Use Committees at Utah State University (No. 10128) and USDA-National Wildlife Research Center (QA-3171).

\section{AUTHOR CONTRIBUTIONS}

ED participated in methodology, data collection, data analysis, writing of the original manuscript draft, and review and editing. PB took part in conceptualization, funding and resource acquisition, supervision, and review and editing. TA participated in methodology, data analysis, and review and editing. JY engaged in conceptualization, methodology, funding, resource acquisition, supervision, and review and editing. All authors contributed to the article and approved the submitted version.

\section{FUNDING}

Funding for this study was provided by the U.S. Bureau of Land Management (Agreement L18AC00121), the Utah Division of Wildlife Resources (in-kind), the U.S. Bureau of Reclamation (Agreement R19AC00153), the Ecology Center at Utah State University, the Utah Chapter of the Wildlife Society, the U.S.

\section{REFERENCES}

Arjo, W. M., Joos, R. E., Kochanny, C. O., Harper, J. L., Nolte, D. L., and Bergman, D. L. (2008). Assessment of transmitter models to monitor beaver Castor canadensis and C. fiber populations. Wildl. Biol. 14, 309-317. doi: 10.2981/09096396(2008)14[309:AOTMTM]2.0.CO;2

Armansin, N. C., Stow, A. J., Cantor, M., Leu, S. T., Klarevas-Irby, J. A., Chariton, A. A., et al. (2020). Social barriers in ecological landscapes: the social resistance hypothesis. Trends Ecol. Evol. 35, 137-148. doi: 10.1016/j.tree.2019. 10.001

Baker, B. W., and Hill, E. P. (2003). "Beaver (Castor canadensis)," in Wild Mammals of North America: Biology, Management, and Conservation $2^{\text {nd }}$ Edn., eds G. A. Feldhamer, B. C. Thompson, and J. A. Chapman (Baltimore, MD: Johns Hopkins University Press), 288-310.

Barela, I. A., and Frey, J. K. (2016). Habitat and forage selection by the American beaver (Castor canadensis) on a regulated river in the Chihuahuan Desert. Southwestern Nat. 61, 286-293. doi: 10.1894/0038-4909-61.4.286

Beer, J. R. (1955). Movements of tagged beaver. J. Wildl. Manage. 19, 492-493.

Berger-Tal, O., Blumstein, D. T., and Swaisgood, R. R. (2020). Conservation translocations: a review of common difficulties and promising directions. Anim. Conserv. 23, 121-131. doi: 10.1111/acv.12534

Bloomquist, C. K., Nielsen, C. K., and Shew, J. J. (2012). Spatial organization of unexploited beavers (Castor canadensis) in Southern Illinois. Am. Midl. Nat. 167, 188-197. doi: 10.1674/0003-0031-167.1.188

Bottcher, J. L. (2009). Maintaining Population Persistence in the Face of an Extremely Altered Hydrograph: Implications for Three Sensitive Fishes in a Tributary of the Green River, Utah. MS thesis, Utah State University, Logan, UT.

Bottcher, J. L., Walsworth, T. E., Thiede, G. P., Budy, P., and Speas, D. W. (2013). Frequent usage of tributaries by the endangered fishes of the Upper Colorado River Basin: observations from the San Rafael River, Utah. N. Am. J. Fish. Mgmt. 33, 585-594. doi: 10.1080/02755947.2013.785993

Bouwes, N., Weber, N., Jordan, C. E., Saunders, W. C., Tattam, I. A., Volk, C., et al. (2016). Ecosystem experiment reveals benefits of natural and simulated beaver
Department of Agriculture-National Wildlife Research Center, and the U.S. Geological Survey, Utah Cooperative Fish and Wildlife Unit (in-kind).

\section{ACKNOWLEDGMENTS}

The authors thank all of the collaborating organizations and involved personnel from those organizations for funding and logistical support. In particular, we are grateful to Gary Thiede (USU, Fish Ecology Lab) for logistical support and to Peter MacKinnon (USU, Biomark Inc.) and Daniel Keller (UDWR) for equipment support during field studies. Special thanks to Annette Roug (UDWR) and the USU Beaver Ecology and Relocation Center, particularly Nate Norman, for their hard work capturing and processing beavers. Thanks to the landowners who granted access to their property for our study and the many volunteers and technicians who assisted in the field. The findings and conclusions in this publication have not been formally disseminated by the U.S. Department of Agriculture and should not be construed to represent any agency determination or policy. This research was approved by the Institute for Animal Use and Care Committees at USDA-National Wildlife Research Center (QA-3171) and Utah State University (\#10128). Any use of trade, firm, or product names is for descriptive purposes only and does not imply endorsement by the United States Government. dams to a threatened population of steelhead (Oncorhynchus mykiss). Sci. Rep. 6, 1-13. doi: 10.1038/srep28581

Breck, S. W., Wilson, K. R., and Andersen, D. C. (2001). The demographic response of bank-dwelling beavers to flow regulation: a comparison on the Green and Yampa rivers. Can. J. Zool. 79, 1957-1964. doi: 10.1139/cjz-79-11-1957

Budy, P., Conner, M. M., Salant, N. L., and Macfarlane, W. W. (2015). An occupancy-based quantification of the highly imperiled status of desert fishes of the southwestern United States. Conserv. Biol. 29, 1142-1152. doi: $10.1111 /$ cobi.12513

Buech, R. R., Rugg, D. J., and Miller, N. L. (1989). Temperature in beaver lodges and bank dens in a near-boreal environment. Can. J. Zool. 67, 1061-1066. doi: 10.1139/z89-147

Burns, C. E. (2005). Behavioral ecology of disturbed landscapes: the response of territorial animals to relocation. Behav. Ecol. 16, 898-905. doi: 10.1093/beheco/ari070

Campbell-Palmer, R., and Rosell, F. (2015). Captive care and welfare considerations for beavers. Zoo Biol. 34, 101-109. doi: 10.1002/zoo.21200

DeStefano, S., Koenen, K. K. G., Henner, C. M., and Strules, J. (2006). Transition to independence by subadult beavers (Castor canadensis) in an unexploited, exponentially growing population. J. Zool. 269, 434-441. doi: 10.1111/j.1469-7998.2006.00160.x

Dickens, M. J., Delehanty, D. J., and Romero, L. M. (2010). Stress: an inevitable component of animal translocation. Biol. Cons. 143, 1329-1341. doi: 10.1016/j.biocon.2010.02.032

Dickie, M., McNay, S. R., Sutherland, G. D., Cody, M., and Avgar, T. (2020) Corridors or risk? Movement along, and use of, linear features varies predictably among large mammal predator and prey species. J. Anim. Ecol. 89, 623-634. doi: 10.1111/1365-2656.13130

Doden, E. (2021). A Comparison of the Ecology of Resident and Translocated Beavers Used for Passive Restoration in Degraded Desert Rivers. M.S. thesis, Utah State University, Logan, UT.

Gibson, P. P., and Olden, J. D. (2014). Ecology, management, and conservation implications of North American beaver (Castor canadensis) in dryland 
streams. Aq. Cons.: Marine and Freshwater Ecosys. 24, 391-409. doi: 10.1002/ aqc. 2432

Graf, P. M., Hochreiter, J., Hackländer, K., Wilson, R. P., and Rosell, F. (2016a). Short-term effects of tagging on activity and movement patterns of Eurasian beavers (Castor fiber). Eur. J. Wildl. Res. 62, 725-736. doi: 10.1007/s10344-016-1051-8

Graf, P. M., Mayer, M., Zedrosser, A., Hackländer, K., and Rosell, F. (2016b). Territory size and age explain movement patterns in the Eurasian beaver. Mamm. Biol. 81, 587-594. doi: 10.1016/j.mambio.2016.07.046

Halley, D. J., Saveljev, A. P., and Rosell, F. (2021). Population and distribution of beavers Castor fiber and Castor canadensis in Eurasia. Mamm. Rev. 51, 1-24. doi: $10.1111 / \mathrm{mam} .12216$

Harper, B. J. (2001). The Ecological Role of Beavers (Castor canadensis) in a Southwestern Desert Stream. M.S. thesis, University of Nevada, Las Vegas, Las Vegas, NV.

Havens, R. P., Crawford, J. C., and Nelson, T. A. (2013). Survival, home range, and colony reproduction of beavers in east-central Illinois, an agricultural landscape. Am. Midl. Nat. 169, 17-29. doi: 10.1674/0003-0031-169.1.17

Heidinger, I. M. M., Poethke, H.-J., Bonte, D., and Hein, S. (2009). The effect of translocation on movement behaviour - a test of the assumptions of behavioural studies. Behav. Processes 82, 12-17. doi: 10.1016/j.beproc.2009.03.001

Herr, J., and Rosell, F. (2004). Use of space and movement patterns in monogamous adult Eurasian beavers (Castor fiber). J. Zool. 262, 257-264. doi: $10.1017 /$ S0952836903004606

Hibbard, E. A. (1958). Movements of beaver transplanted in North Dakota. J. Wildl. Manage. 22, 209-211. doi: 10.2307/3797335

Kaczensky, P., Salemgareyev, A., Linnell, J. D. C., Zuther, S., Walzer, C., Huber, N., et al. (2021). Post-release movement behaviour and survival of kulan reintroduced to the steppes and deserts of central Kazakhstan. Front. Conserv. Sci. 2, 703358. doi: 10.3389/fcosc.2021.703358

Knudsen, G. J., and Hale, J. B. (1965). Movements of transplanted beavers in Wisconsin. J. Wildl. Manage. 29, 685-688. doi: 10.2307/3798542

Korbelová, J., Hamš́ḱvová, L., Malon, J., Válková, L., and Vorel, A. (2016). Seasonal variation in the home range size of the Eurasian beaver: do patterns vary across habitats? Mamm. Res. 61, 243-253. doi: 10.1007/s13364-016-0265-1

Kukalová, M., Gazárková, A., and Adamík, P. (2013). Should I stay or should I go? The influence of handling by researchers on den use in an arboreal nocturnal rodent. Ethology 119, 848-859. doi: 10.1111/eth.12126

Larsen, A., Larsen, J. A., and Lane, S. N. (2021). Dam builders and their works: beaver influences on the structure and function of river corridor hydrology, geomorphology, biogeochemistry, and ecosystems. Earth Sci. Rev. 218: 103623. doi: 10.1016/j.earscirev.2021.103623

Laub, B. G. (2015). Lower San Rafael River and Riparian Corridor Restoration: BLM Land Phase 1. Report Utah Water Restoration Initiative.

Laub, B. G. (2018). Lower San Rafael River and riparian Corridor Habitat Improvement: Phase 1a. Report Utah Water Restoration Initiative.

Le Gouar, P. L., Mihoub, J. B., and Sarrazin, F. (2012). "Dispersal and habitat selection: Behavioural and spatial constraints for animal translocations". In Reintroduction biology: Integrating science and management, eds. J. G. Ewen, D. P. Armstrong, K. A. Parker, and P. J. Seddon (Oxford: Wiley-Blackwell) 138-164.

Lee, H. N., Greggor, A. L., Masuda, B., and Swaisgood, R. R. (2021). Anti-predator vigilance as an indicator of the costs and benefits of supplemental feeding in newly released 'Alalā (Corvus hawaiiensis). Front. Conserv. Sci. 2, 701490. doi: $10.3389 /$ fcosc. 2021.701490

Leege, T. A. (1968). Natural movements of beavers in Southeastern Idaho. J. Wildl. Manage. 32, 973-976. doi: 10.2307/3799579

Lesica, P., and Miles, S. (2004). Beavers indirectly enhance the growth of Russian olive and tamarisk along eastern Montana rivers. Western North Am. Nat. $64,93-100$.

Lyster, S. (2018). San Rafael River Restoration Project Progress Report: Gravel Study. Report Utah State University, Logan.

Macfarlane, W. W., Wheaton, J. M., Bouwes, N., Jensen, M. L., Gilbert, J. T., Hough-Snee, N., et al. (2017). Modeling the capacity of riverscapes to support beaver dams. Geomorphology 277, 72-99. doi: 10.1016/j.geomorph.2015. 11.019

Maenhout, J. (2013). Beaver Ecology in Bridge Creek, a Tributary to the John Day River. MS Thesis, Oregon State University, Corvallis, OR.
Matykiewicz, B. R., Windels, S. K., Olson, B. T., Plumb, R. T., Wolf, T. M., and Ahlers, A. A. (2021). Assessing translocation effects on the spatial ecology and survival of muskrats Ondatra zibethicus. Wildl. Biol. 2021, wlb-00823. doi: $10.2981 /$ wlb.00823

Mayer, M., Zedrosser, A., and Rosell, F. (2017). When to leave: the timing of natal dispersal in a large, monogamous rodent, the Eurasian beaver. Anim. Behav. 123, 375-382. doi: 10.1016/j.anbehav.2016.11.020

McClintic, L. F., Taylor, J. D., Jones, J. C., Singleton, R. D., and Wang, G. (2014a). Effects of spatiotemporal resource heterogeneity on home range size of American beaver. J. Zool. 293, 134-141. doi: 10.1111/jzo.12128

McClintic, L. F., Wang, G., Taylor, J. D., and Jones, J. C. (2014b). Movement characteristics of American beavers (Castor canadensis). Behaviour 151, 1249-1265. doi: 10.1163/1568539X-00003183

McKinstry, M. C., and Anderson, S. H. (2002). Survival, fates, and success of transplanted beavers, Castor canadensis, in Wyoming. Can. Field Nat. $116,60-68$

McNew, L. B. Jr., and Woolf, A. (2005). Dispersal and survival of juvenile beavers (Castor canadensis) in Southern Illinois. Am. Midl. Nat. 154, 217-228. doi: 10. 1674/0003-0031(2005)154[0217:DASOJB]2.0.CO;2

McNicol, C. M., Bavin, D., Bearhop, S., Bridges, J., Croose, E., Gill, R., et al. (2020). Postrelease movement and habitat selection of translocated pine martens Martes Post release. Ecol. Evol. 10, 5106-5118. doi: 10.1002/ece3.6265

Mihoub, J. B., Robert, A., Le Gouar, P., and Sarrazin, F. (2011). Post-release dispersal in animal translocations: Social attraction and the "vacuum effect." PLoS ONE 6, e27453. doi: 10.1371/journal.pone.0027453

Mills, L. S., Soulé, M. E., and Doak, D. F. (1993). The keystone-species concept in ecology and conservation. BioScience 43, 219-224. doi: 10.2307/1312122

Moehrenschlager, A., and Macdonald, D. W. (2003). Movement and survival parameters of translocated and resident swift foxes Vulpes velox. Anim. Conserv. 6, 199-206. doi: 10.1017/S1367943003003251

Mott Lacroix, K. E., Tapia, E., and Springer, A. (2017). Environmental flows in the desert rivers of the United States and Mexico: synthesis of available data and gap analysis. J. Arid Env. 140, 67-78. doi: 10.1016/j.jaridenv.2017.01.011

Nagler, P., Glenn, E. P., Thompson, T. L., and Huete, A. (2004). Leaf area index and normalized difference vegetation index as predictors of canopy characteristics and light interception by riparian species on the Lower Colorado River. Agricult. and Forest Meteorol. 125, 1-17. doi: 10.1016/j.agrformet.2004.03.008

Naiman, R. J., Johnston, C. A., and Kelley, J. C. (1988). Alteration of North American streams by beaver. BioScience 38, 753-762. doi: 10.2307/1310784

Nash, C. S., Grant, G. E., Charnley, S., Dunham, J. B., Gosnell, H., Hausner, M. B., et al. (2021). Great expectations: deconstructing the process pathways underlying beaver-related restoration. BioScience 71, 249-267. doi: 10.1093/biosci/biaa165

Nathan, R. (2008). An emerging movement ecology paradigm. Proc. Natl. Acad. Sci USA. 105, 19050-19051. doi: 10.1073/pnas.0808918105

National Oceanic and Atmospheric Administration (2021). Data tools: 1981-2010 Annual/Seasonal Normals. National Centers for Environmental Information. Available online at: https://www.ncdc.noaa.gov/cdo-web/datatools/normals (accessed April 4, 2021).

Neumann, W., Martinuzzi, S., Estes, A. B., Pidgeon, A. M., Dettki, H., Ericsson, G., et al. (2015). Opportunities for the application of advanced remotely-sensed data in ecological studies of terrestrial animal movement. Mov. Ecol. 3, 8. doi: 10.1186/s40462-015-0036-7

Patric, E. F., and Webb, W. L. (1960). An evaluation of three age determination criteria in live beavers. J. Wildl. Manag. 24, 37-44. doi: 10.2307/3797354

Pennock, C., Budy, P., Macfarlane, W. W., Breen, M. J., Jimenez, J., and Schmidt, J. C. (2021). Native fish need a natural flow regime, not more water development. Fish. Magazine. doi: 10.1002/fsh.10703

Petro, V. M., Taylor, J. D., and Sanchez, D. M. (2015). Evaluating landowner-based beaver relocation as a tool to restore salmon habitat. Glob. Ecol. Conserv. 3, 477-486. doi: 10.1016/j.gecco.2015.01.001

Pettorelli, N., Ryan, S., Mueller, T., Bunnefeld, N., Jedrzejewska, B., Lima, M., et al. (2011). The Normalized Difference Vegetation Index (NDVI): unforeseen successes in animal ecology. Clim. Res. 46, 15-27. doi: 10.3354/cr00936

Pilliod, D. S., Rohde, A. T., Charnley, S., Davee, R. R., Dunham, J. B., Gosnell, H., et al. (2018). Survey of beaver-related restoration practices in rangeland streams of the Western USA. Environ. Manag. 61, 58-68. doi: 10.1007/s00267-017-0957-6 
Pinheiro, J., Bates, D., DebRoy, S., Sarkar, D., and and, R., Development Core Team (2013). nlme: Linear and Nonlinear Mixed Effects Models. R package version 3.1.152. Available online at: https://cran.r-project.org/package=nlme (accessed March 22, 2021)

Pollock, M. M., Beechie, T. J., Wheaton, J. M., Jordan, C. E., Bouwes, N., and Weber, N., et al. (2014). Using beaver dams to restore incised stream ecosystems. BioScience 64, 279-290. doi: 10.1093/biosci/biu036

Pollock, M. M., Lewallen, G. M., Woodruff, K., Jordan, C. E., and Castro, J. M. (2018). The Beaver Restoration Guidebook: Working with Beaver to Restore Streams, Wetlands, and Floodplains Version 2.01. Portland, OR: United States Fish and Wildlife Service.

Prokopenko, C. M., Boyce, M. S., and Avgar, T. (2017). Characterizing wildlife behavioural responses to roads using integrated step selection analysis. J. Appl. Ecol. 54, 470-479. doi: 10.1111/1365-2664.12768

R Development Core Team (2020). R: A Language and Environment for Statistical Computing. Vienna: R Foundation for Statistical Computing. Available online at: https://www.R-project.org/ (accessed January 18, 2021).

Ritter, T. D. (2018). Ecosystem Pioneers: Beaver Dispersal and Settlement Site Selection in the Context of Habitat Restoration. M.S. Thesis, Montana State University, Bozeman, MT.

Ritter, T. D., Gower, C. N., and McNew, L. B. (2020). Habitat conditions at beaver settlement sites: implications for beaver restoration projects. Restor. Ecol. 28, 196-205. doi: 10.1111/rec.13032

Rosell, F., Bozser, O., Collen, P., and Parker, H. (2005). Ecological impact of beavers Castor fiber and Castor canadensis and their ability to modify ecosystems. Mamm. Rev. 35, 248-276. doi: 10.1111/j.1365-2907.2005.00067.x

Rothmeyer, S. W., McKinstry, M. C., and Anderson, S. H. (2002). Tail attachment of modified ear-tag radio transmitters on beavers. Wildl. Soc. Bull. 30, 425-429.

Roug, A., Talley, H., Davis, T., Roueche, M., and DeBloois, D. (2018). A mixture of butorphanol, azaperone, and medetomidine for the immobilization of American Beavers (Castor canadensis). J. Wildl. Dis. 54, 617-621. doi: 10.7589/2017-12-296

Schulte, B. A., Müller-Schwarze, D., and Sun, L. (1995). Using anal gland secretion to determine sex in beaver. J. Wildl. Manage. 59, 614-618. doi: 10.2307/3802470

Seddon, P. J., Griffiths, C. J., Soorae, P. S., and Armstrong, D. (2014). Reversing defaunation: restoring species in a changing world. Science 354, 406-412. doi: $10.1126 /$ science. 1251818

Street, G. M., Avgar, T., and Börger, L. (2018). Net displacement and temporal scaling: model fitting, interpretation and implementation. Methods Ecol. Evol. 9, 1503-1517. doi: 10.1111/2041-210X.12978

Stromberg, J. C. (2001). Restoration of riparian vegetation in the south-western United States: importance of flow regimes and fluvial dynamism. J. Arid Environ. 49, 17-34. doi: 10.1006/jare.2001.0833

Sun, L., Müller-Schwarze, D., and Schulte, B. A. (2000). Dispersal pattern and effective population size of the beaver. Can. J. Zool. 78, 393-398. doi: 10.1139/cjz-78-3-393

Swinnen, K. R. R., Hughes, N. K., and Leirs, H. (2015). Beaver (Castor fiber) activity patterns in a predator-free landscape: what is keeping them in the dark? Mamm. Biol. 80, 477-483. doi: 10.1016/j.mambio.2015.07.006

Tyers, M. B. (2016). Riverdist: River Network Distance Computation and Applications. R Package version 0.15.3. Available online at: https://cran.rproject.org/package=riverdist (accessed January 18, 2021).
United States Geological Survey (2017). EROS Science Processing Architecture on Demand Interface. Available online at: https://espa.cr.usgs.gov/ (accessed May $18,2021)$.

United States Geological Survey (2021a). USGS Current Water Data for Utah. National Water Information System: Web Interface. Available online at: https:// waterdata.usgs.gov/ut/nwis/rt (accessed March 12, 2021).

United States Geological Survey (2021b). USGS Earth Explorer. Available online at: https://earthexplorer.usgs.gov/ (accessed May 18, 2021).

Utah Division of Wildlife Resources (2017). Protocol for Live Trapping, Holding and Transplanting Beaver. Report Utah Division of Wildlife Resources.

Walker, C. A., and Hudson, M. (2004). Surveys to Determine the Current Distribution of the Roundtail Chub, Flannelmouth Sucker, and Bluehead Sucker in the San Rafael Drainage, During 2003. Report Utah Division of Wildlife Resources, Salt Lake City.

Wang, G., McClintic, L. F., and Taylor, J. D. (2019). Habitat selection by American beaver at multiple spatial scales. Anim. Biotelem. 7, 1-8. doi: 10.1186/s40317-019-0172-8

Weilenmann, M., Gusset, M., Mills, D. R., Gabanapelo, T., and Schiess-Meier, M. (2010). Is translocation of stock-raiding leopards into a protected area with resident conspecifics an effective management tool? Wildl. Res. 37, 702-707. doi: 10.1071/WR10013

Windels, S. K., and Belant, J. L. (2016). Performance of tail-mounted transmitters on American beavers Castor canadensis in a northern climate. Wildl. Biol. 22 124-129. doi: 10.2981/wlb.00159

Woodford, J. E., MacFarland, D. M., and Worland, M. (2013). Movement, survival, and home range size of translocated American martens (Martes americana) in Wisconsin. Wildl. Soc. Bull. 37, 616-622. doi: 10.1002/ wsb. 291

Woodruff, K., and Pollock, M. M. (2018). "Relocating beaver," in The Beaver Restoration Guidebook: Working with Beaver to Restore Streams, Wetlands, and Floodplains, eds M. M. Pollock, G. M. Lewallen, K. Woodruff, C. E. Jordan, and J. M. Castro (Portland, OR: United States Fish and Wildlife Service), $64-84$.

Conflict of Interest: The authors declare that the research was conducted in the absence of any commercial or financial relationships that could be construed as a potential conflict of interest.

Publisher's Note: All claims expressed in this article are solely those of the authors and do not necessarily represent those of their affiliated organizations, or those of the publisher, the editors and the reviewers. Any product that may be evaluated in this article, or claim that may be made by its manufacturer, is not guaranteed or endorsed by the publisher.

Copyright $\odot 2022$ Doden, Budy, Avgar and Young. This is an open-access article distributed under the terms of the Creative Commons Attribution License (CC BY). The use, distribution or reproduction in other forums is permitted, provided the original author(s) and the copyright owner(s) are credited and that the original publication in this journal is cited, in accordance with accepted academic practice. No use, distribution or reproduction is permitted which does not comply with these terms. 